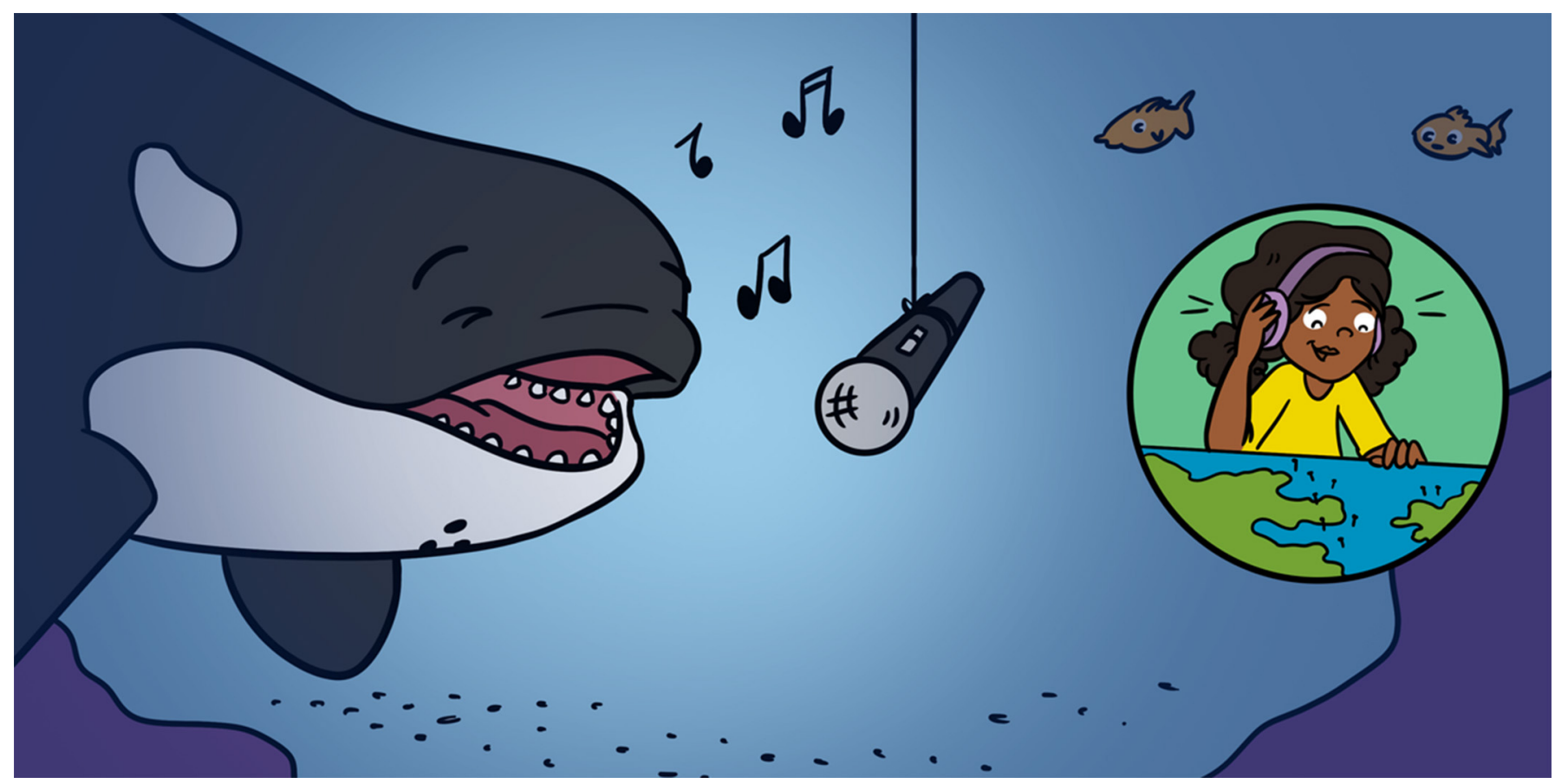

\title{
LEARNING ABOUT WHALES BY LISTENING FOR THEIR CALLS
}

\section{Rianna Burnham *}

Geography Department, The Whale Research Lab, University of Victoria, Victoria, BC, Canada

\section{YOUNG REVIEWER:}

JUNIPER

AGE: 10
Populations of large whales have been reduced to very low numbers, primarily by hunting. As the number of whales became smaller, they became harder to find. In the past, whalers knew where to go to hunt, but now scientists who study whales can find it hard to know which areas whales use to feed, breed, or even travel through. We now realize how important whales are for keeping oceans healthy, so scientists are trying to learn as much as they can about large whales. Underwater sound recordings are helping us find some of the rarest whales in the northeast Pacific by listening for their calls. We use underwater microphones, called hydrophones, set on the ocean floor and on ocean gliders, which are small submarines, to help us learn about where whales are, when they are there, and most importantly, what they are doing.

\section{WHALES HUNTED ALMOST TO EXTINCTION}

Whales were once hunted for oil, meat, and many other things that people used in everyday life. Whalers killed many whales, decreasing 
CONTINENTAL

SHELE

The shallow areas of the ocean closest to land. The ocean floor is a gentle slope away from the coast, with water usually $<200 \mathrm{~m}$ deep. The shelf comes to an end with a steep drop and a rapid increase in water depth, forming a cliff face known as the continental shelf break.

\section{HYDROPHONE}

An underwater microphone used to make recordings of the sounds of the ocean.

\section{GLIDER}

A survey tool that can be controlled by scientists. The glider looks a bit like a submarine and can move around the ocean using batteries for power, going up and down in the water as it moves.

\section{CANYON}

A crack in the cliff face formed by the continental shelf break whale populations until many large whale species almost became extinct. Despite the end of hunting over-30 years ago, some of these species still only survive in small numbers. Some species are so rare that scientists do not know how many whales there are in the population, where they live, how they move through the oceans, or if they have special areas to feed, breed, and raise their calves. Some whales, like gray and humpback whales, live closer to the land in shallower waters where the sea floor is a gentle, sandy slope away from the coast. This area is called the continental shelf. Whales living on the continental shelf have recovered from whaling and are fairly easy to study. But whales, such as blue whales and fin whales are large and live in deeper waters far from the coast, called offshore areas. At the end of the continental shelf is a steep drop that creates a cliff face under water, where the water becomes very deep very quickly. This is called the continental shelf break. It is here that the larger whales like to live, which makes it very hard for scientists to study them.

\section{WHALES CAN BE HARD TO FIND!}

The first thing we need to know to help save whales from extinction is how many of each type of whale there are, and where they are located. You might think it would be easy to count very large whales, but they can be hard to find in the deep offshore waters. Scientists also want to know where whales might get together to be social, feed, and breed, as these actions are very important for whales' survival. Scientists also want to know other things, like whether the whales have enough food, and whether people are changing the oceans in ways that make it harder for whales to live.

Sometimes scientists cannot look for the whales in person-it might be hard, dangerous, or just too far. Instead, we use underwater microphones, called hydrophones, to listen for them. We will describe how hydrophones were used to listen for whale calls in the Canadian Pacific Ocean, off the coast of Vancouver Island. These hydrophones were located both on the ocean floor and on ocean gliders, which are small submarines. One of the hydrophones on the ocean floor was fairly close to land and the other was at the bottom of the steep continental shelf break. The glider can be controlled from land, and we moved it between these two hydrophones to survey for whales, listening for their calls (Figure 1). The hydrophones on the sea floor recorded all the time, but the glider could only record for a month before its batteries needed replacing. We used the gliders to survey twice, once in the spring (Figure 1, red line) and once in the winter (Figure 1, blue line). We listened on the continental shelf in shallow water, past the continental shelf in deep water, and in cracks in the cliff face of the continental shelf break, called canyons. Sometimes the small animals that whales eat get trapped in these canyon cracks because of the way the water moves inside them, and so we thought whales might be there to feed. 
Figure 1

Location of hydrophones (stars) on the ocean floor and glider survey tracks from our experiments. The spring survey is shown in red and the winter shown in blue. The continental shelf break (black line) is shown to indicate where shallow coastal waters change to deep, offshore waters.

\section{PITCH}

How high or low a sound is. For example, when a dog whines, it is a high pitch, when it growls, it is a low pitch.

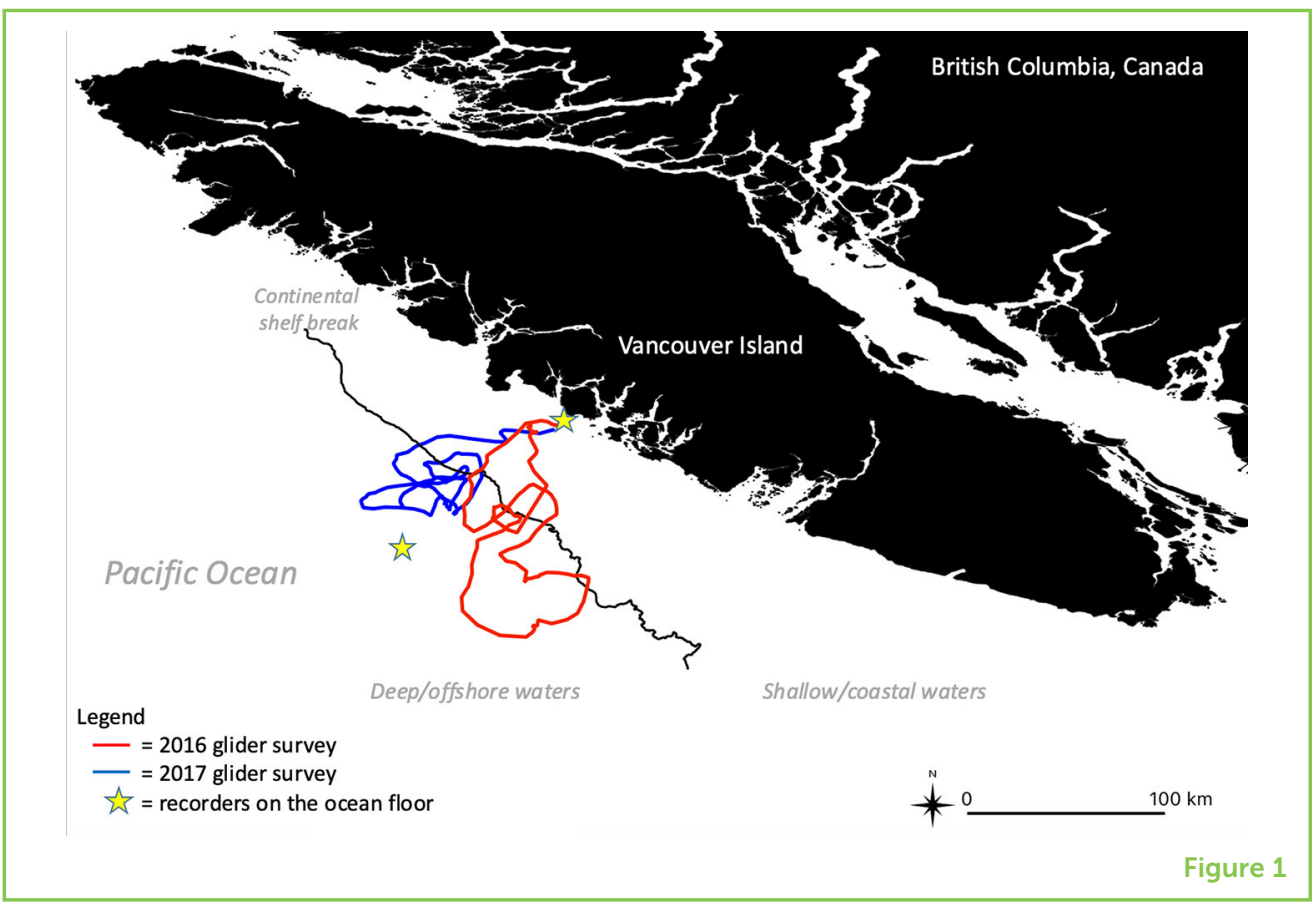

We were hoping to hear blue, fin, sei, and sperm whale calls. Each whale species makes a specific sound, which means we know which whales we are hearing. These calls can be high or low in pitch, long or short, they can go up-and-down or be flat in pitch, or they can sound like a whistle, a moan, or a click (Figure 2). The larger whales, like blue and fin, make long, low, moans that go down in pitch. Smaller whales and dolphins, such as killer whales make short, higher-pitched whistles, and humpback whales make moans and whistles that change in pitch. Sperm whales and the other smaller toothed whales use clicks. Whales' calls can also help us learn what the whales are doing. Some calls are used more frequently when whales are traveling or mating, and other calls tell us that they are feeding.

\section{LOCATING WHALES AND IDENTIFYING THEIR ACTIVITIES}

In the spring, on the first glider survey (Figure 1, red line), we heard gray whales first, as they called to each other while traveling along the coast of North America to their feeding areas in the Arctic. As the glider got further away from shore, we heard humpback whales, then when the glider went into even deeper waters, we heard what was most likely the feeding calls of fin and blue whale calls (Figure 2; [1]). A few faint sei whale calls were also heard. Many sei whales were killed back when whales were hunted, and they have not been seen very much at all since the 1950s. From the hydrophones on the ocean floor, we heard smaller whale species closer to the coast and larger whales in waters past the continental shelf break (Figure 3). The deeper hydrophone on the ocean floor also heard lots of sperm whale and dolphin clicks. 
Figure 2

Pictures of the sounds that the whales were heard making, showing the pitch range of the calls and how the pitch changed during the call. The top panel shows humpback and killer whale calls heard during the surveys. The humpback calls are in the lower pitches (at the bottom of the picture) and killer whale calls are higher in pitch, in the mid-range. In the lower panels, blue and fin whale calls are shown. These are very low calls, lower than those of both humpback and killer whales.

\section{Figure 3}

Ocean depths and locations where whale species were most heard by the hydrophones and the glider during the surveys. You can see the gentle slope of the continental shelf, the sharp drop of the continental shelf break, and the cracks in the shelf break that form canyons (this drawing is not exactly to scale).
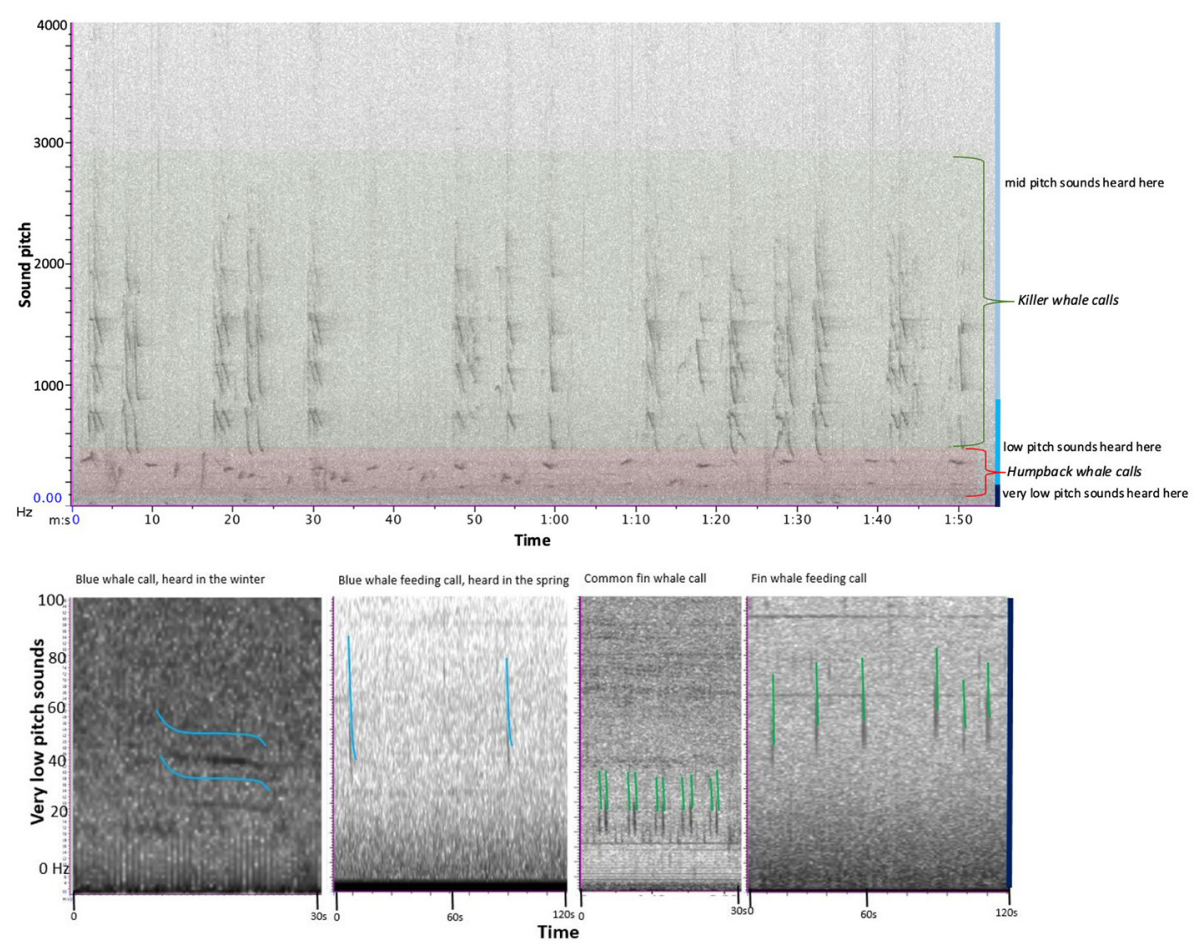

Figure 2

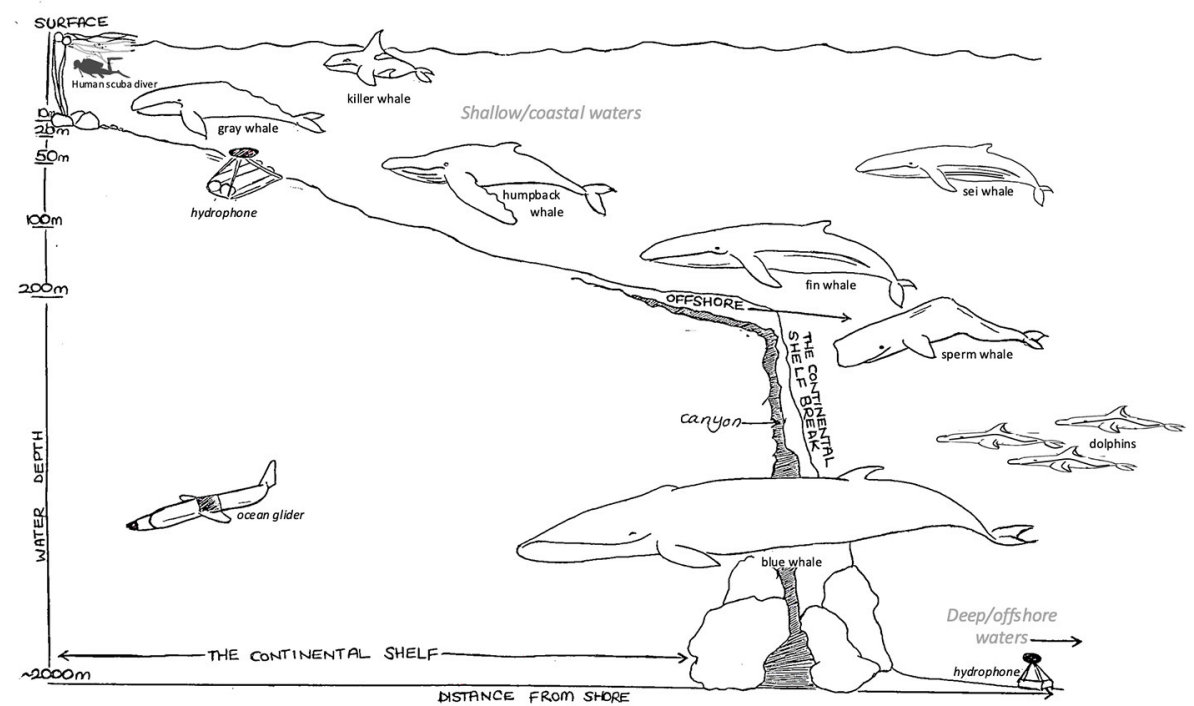

Figure 3

After the excitement of the first glider survey, we prepared for our second, this time in the winter! For this survey, we wanted to further explore the canyon cracks of the continental shelf break (Figure 1, blue line), because we heard lots of calls in this area in the spring. We were curious as to whether we would hear the same whales in the winter as in the spring. In the spring the fin, blue and sperm whale calls had been mostly in the offshore waters, and fin whales heard the most when the glider was surveying in canyons. On this second survey, we heard lots more calls. The general patterns were the same as the first survey, 
with gray and humpback whales heard when the glider was closest to shore, and the bigger whales recorded in the deepest waters. We even heard sperm whales hunting! When hunting, their clicks get closer and closer, until they form a "buzz," just before the whale catches the fish or squid it is chasing.

Once we knew where we were most likely to hear each whale species, the next step was to understand what the whales were doing when we heard them, and if the areas off Vancouver Island are important to them. Calls used during feeding were heard from fin and blue whales (Figure 2) in the spring and from sperm whales all year round. Mating "song" calls were heard in the winter from male fin whales to attract females [1], and travel calls were heard from gray whales as they migrated. This means that these areas of the ocean might be very important for whale survival.

\section{SOUNDS FROM HYDROPHONE RECORDINGS CAN HELP SAVE WHALES}

Using recordings from hydrophones is a very good way to get information about whales. Using these instruments, we can survey in bad weather and in the dark, which would be very hard or impossible if we were in a boat or plane. But there are a few things we cannot tell just from listening to hydrophone recordings. When we hear a call, we know there is a whale in that location, but unless we hear lots of calls together, we do not know whether there is more than one whale. Also, hearing lots of calls does not mean there are lots of whales, we could just be listening to one very chatty whale! Whales might not call as much when they are eating and they may call more when they are trying to find other whale friends or a mate.

We heard thousands of whale calls in our experiments, and this told us when and where whales were and, in some cases, what they were doing, but there may be many more whales that we did not hear. The more surveys we do, and the more we listen to the oceans, the more we will know about whales and how they use these areas. Protection of these areas of the oceans might help whale numbers grow and species to survive. For example, areas that are important to the whales could be conserved as sanctuaries or marine protected areas or, for species closer to shore, rules about boating near whales may reduce the disturbance caused by humans. In general, our work and the work of other scientists can help conservationists and decision makers establish ways to protect whales, so that they will be around and healthy for many years to come.

\section{ORIGINAL SOURCE ARTICLE}

Burnham, R. E., Duffus, D. A., and Mouy, X. 2019. The presence of large whale species in Clayoquot sound and its offshore waters. Cont. Shelf Res. 177:15-23. doi: 10.1016/j.csr.2019.03.004 


\section{REFERENCES}

1. Burnham, R. E. 2019. Temporal variation in fin whale calling in Clayoquot sound and its offshore waters. Northwest Sci. 93:66-74. doi: 10.3955/046.093.0106

SUBMITTED: 05 October 2019; ACCEPTED: 27 March 2020; PUBLISHED ONLINE: 24 April 2020.

EDITED BY: Carolyn Scheurle, Institut de la Mer de Villefranche (IMEV), France

CITATION: Burnham R (2020) Learning About Whales by Listening for Their Calls. Front. Young Minds 8:55. doi: 10.3389/frym.2020.00055

CONFLICT OF INTEREST: The author declares that the research was conducted in the absence of any commercial or financial relationships that could be construed as a potential conflict of interest.

COPYRIGHT @ 2020 Burnham. This is an open-access article distributed under the terms of the Creative Commons Attribution License (CC BY). The use, distribution or reproduction in other forums is permitted, provided the original author(s) and the copyright owner(s) are credited and that the original publication in this journal is cited, in accordance with accepted academic practice. No use, distribution or reproduction is permitted which does not comply with these terms.

\section{YOUNG REVIEWER}

\section{JUNIPER, AGE: 10}

I like reading and coding. I also like animals. My favorite subjects in school are mathematics and art. My favorite art activities are paper marbling and modeling clay.

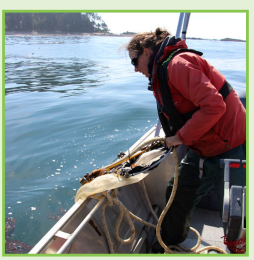

\section{AUTHOR}

\section{RIANNA BURNHAM}

Dr. Rianna Burnham is an ecologist who uses passive acoustic monitoring techniques to add to what is known about marine ecosystems. She currently works as a research scientist for the Department of Fisheries and Oceans Canada. She has worked for more than 10 years on the west coast of British Columbia studying the behaviors of and habitat use by whales, and has increasingly become interested in how science can inform conservation and management actions. *rburnham31@gmail.com 